\title{
ANÁLISIS Y RESTITUCIÓN INFOGRÁFICA DEL ESPACIO DE LA ESCALERA PRINCIPAL DEL CASTILLO DE VÉLEZ BLANCO (ALMERÍA)
}

\author{
Ismael Motos Díaz \\ Universidad de Granada
}

\begin{abstract}
El objetivo de este trabajo es analizar y restituir mediante modelos infográficos el espacio de la escalera principal del castillo de Vélez Blanco con el fin de recrear las cualidades espaciales, lumínicas y materiales originales de este ámbito. Si de la estancia primitiva se conserva poco más que el perímetro murario que lo acota, esta investigación identifica y reconstruye virtualmente cada una de las partes y elementos que la conformaban a partir del estudio histórico-documental y el levantamiento tridimensional del estado actual de la sala y de las piezas de la escalera que aún se conservan desmontadas en otras dependencias del castillo.

Palabras clave: Escalera principal; Castillo; Vélez Blanco; Marqués de los Vélez; Pedro Fajardo; Renacimiento español.
\end{abstract}

\section{ANALYSIS AND RESTITUTION VIA COMPUTER GRAPHICS OF THE ARCHITECTURAL SPACE OF THE MAIN STAIRCASE OF THE CASTLE OF VÉLEZ BLANCO (ALMERÍA)}

The aim of this project was to analyze and restore the architectural space of the main staircase of the castle of Vélez using Rendering (a process of generating an image from a model by means of computer programs) in order to recreate the spatial, light and material qualities of the original room. Virtually the only intact structures that remain in the building are the walls. Therefore, the main focus of this research was the identification and creation of a virtual reconstruction of all the architectural elements that initially formed part of the main staircase space. The author has carried out a historical study and has made a three-dimensional survey of the current state of the remains of the staircase along with the pieces of marble from this room that have been preserved but disassembled in other areas of the castle.

Key words: Main staircase; Castle; Velez Blanco; Marquis of los Velez; Pedro Fajardo; Spanish Renaissance.

Desde mi formación y experiencia como arquitecto, considero que conocer una obra arquitectónica requiere visitarla, captar los estímulos sensoriales que transmite y percibir el espacio en conjunción con la luz y la materialidad que lo construye. En la actualidad, estas experiencias no son posibles vivirlas en el castillo de Vélez Blanco. La imagen desnuda que ofrecen hoy por hoy los interiores del edificio tras el deterioro sufrido, la venta de sus bienes más valiosos y las sucesivas intervenciones inacabadas de restauración, no corresponde con la riqueza con que contó después de su construcción 1515. 
El objetivo del trabajo que a continuación desarrollo es analizar y restituir mediante modelos infográficos el espacio de la escalera principal con el fin de recrear las cualidades espaciales, lumínicas y materiales originales de este ámbito. Desgraciadamente, del espacio de la escalera principal original queda poco más que el perímetro murario que lo acota, el suelo de la planta baja sobre el que gravita y las bóvedas estructurales de la escalera primitiva. Por tanto, el grueso de este proyecto consiste en identificar, analizar y reconstruir mediante programas informáticos de modelado tridimensional cada una de las partes y elementos que lo conformaban.

Pero sin duda, la complejidad de este trabajo no está en el uso de estas herramientas 3D, sino en formular las preguntas adecuadas y resolverlas mediante el análisis histórico-documental pues sólo así, es posible conseguir infografías científicas. Por ello, he recopilado e interpretado aquellos documentos que aportan datos y reflexiones sobre el espacio de la escalera de forma directa o indirecta y que he encontrado en diferentes archivos y fondos bibliográficos, hemerográficos y fototecas tales como el Archivo General de la Administración, el Archivo General de la Fundación Casa Medina Sidonia o el Archivo del Patronato de la Alhambra y el Generalife.

El castillo de Vélez Blanco fue construido entre 1506 y 1515 por Pedro Fajardo y Chacón quien fue nombrado Marqués de los Vélez en 1507. Criado en la corte, fue paje de la reina Isabel la Católica y alumno de Pedro Mártir de Anglería, maestro que le hizo conocedor de la cultura humanista. Con el fin de convertir a Vélez Blanco en el centro administrativo y de gobierno de sus dominios, Fajardo erigió sobre la antigua alcazaba musulmana un fabuloso castillo con un patio central renacentista de estilo importado directamente de Italia concebido para representar la grandeza y los valores culturales del señor más influyente del sureste peninsular. A partir de mediados del siglo XVI, los nuevos centros de poder alejaron a los herederos del marquesado de Vélez Blanco provocando el progresivo abandono y deterioro del castillo. Este hecho dio lugar a que la casa de Medina Sidonia, la por entonces propietaria, vendiera en 1903 y 1904 al anticuario francés J. Golberg los elementos escultóricos de mármol blanco de Macael que componían el patio entre otras piezas de gran valor. En 1913, George Blumenthal, coleccionista y posteriormente presidente de The Metropolitan Museum of Art de Nueva York, los adquirió en París y los instaló en su casa de Manhattan. En 1945, después de su muerte y la demolición de su residencia, las piezas del patio fueron trasladadas al museo donde fueron instaladas en 1964.

A pesar del paso del tiempo, el castillo de Vélez Blanco siempre ha conservado su magnífica envolvente exterior pétrea de sillares y mampostería que configura una planta irregular adaptada al abrupto relieve del cerro sobre el que se ubica. Desde el exterior, podemos distinguir claramente dos recintos situados a distinta cota, de desigual altura y con lenguajes arquitectónicos diferentes. En el interior del recinto norte, el de mayor altura, se inserta el patio que es el espacio arquitectónico que estructura las distintas partes del conjunto. Adjunto a él, se encuentra el espacio de la escalera principal.

Para comprender la importancia que la escalera principal tiene en el organigrama del castillo de Vélez Blanco es fundamental conocer la función de los espacios anexos a ella. Esta información es posible conocerla gracias al texto que recoge la visita del VI marqués Fernando Joaquín Fajardo al castillo en 1657. Este documento que a continuación trato es una descripción detallada de algunas estancias del edificio cuyo manuscrito original se encuentra en el Archivo General de la Fundación Casa Medina Sidonia (Legajo 513, sin foliar) ${ }^{1}$. El texto posee un valor excepcional pues permite conocer el uso, denominación y ubicación de algunos espacios del castillo. En él, se enumera una sucesión de habitaciones concatenadas que esbozan una planta compartimentada que contrasta con la imagen que ofrece el castillo en la actualidad donde, tras la destrucción y restauración del edificio, no existen elementos divisorios y el volumen espacial lo configura únicamente el esqueleto murario estructural. A continuación, recojo extractos de este documento y represento gráficamente el itinerario que realizó el VI marqués (fig. 1): "Llegose al puente del dicho castillo, que es de

\footnotetext{
${ }^{1}$ Transcripción publicada en Roth, 2007: 82.
}

Arch. esp. arte, LXXXVIII, 351, JULIO-SEPTIEMBRE 2015, 223-242 ISSN: 0004-0428, eISSN: 1988-8511, doi: 10.3989/aearte.2015.14 


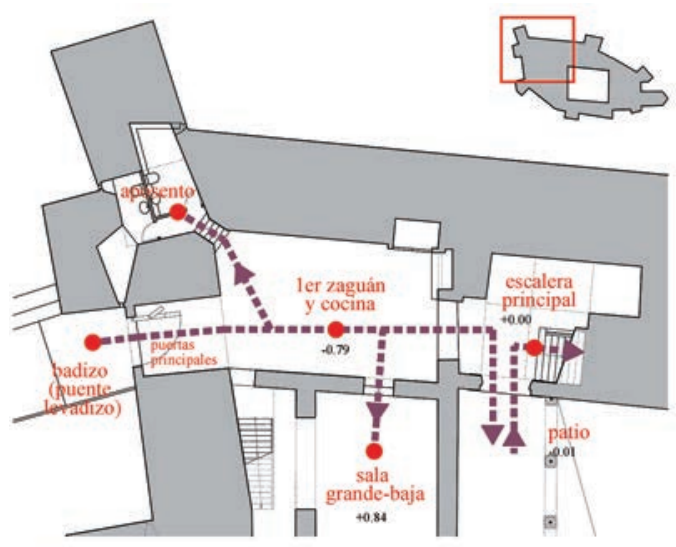

NIVEL $1 \quad(+7.80 y+9,46)$

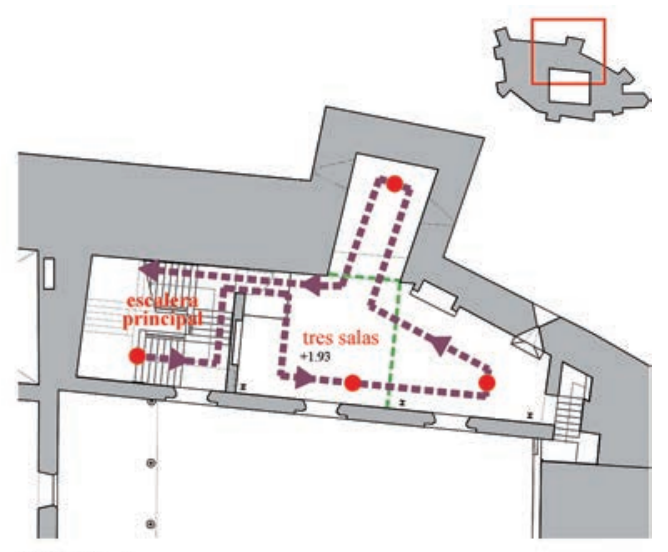

NIVEL 2 (+11.78)
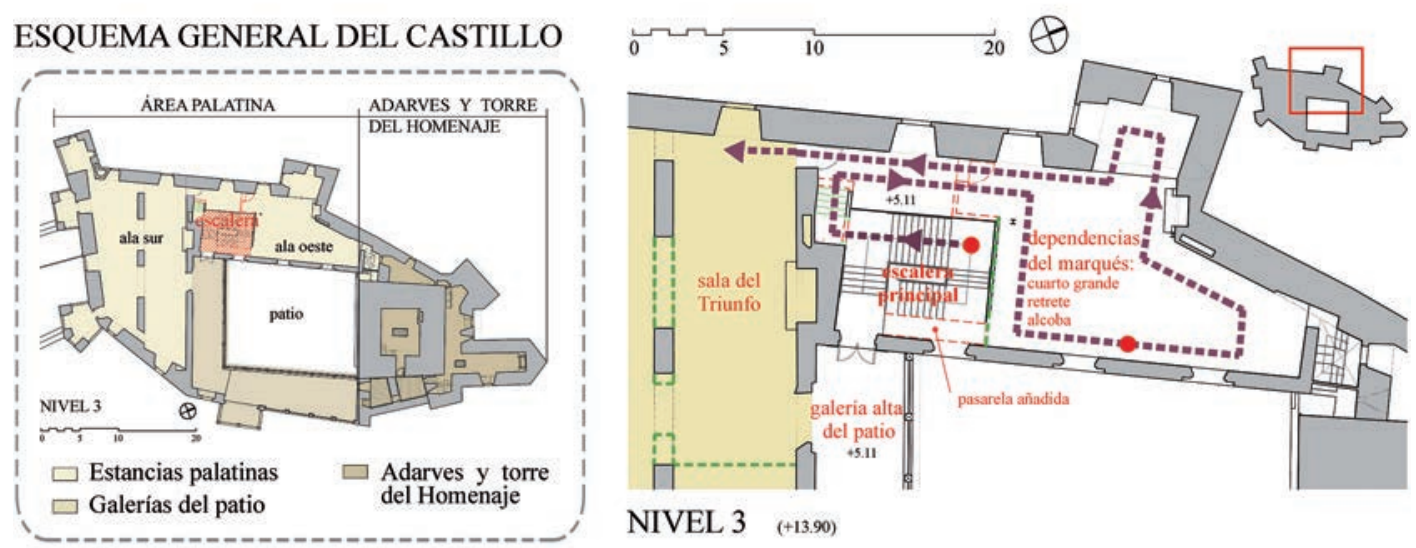

NIVEL $3 \quad(+13.90)$

\section{leyenda}

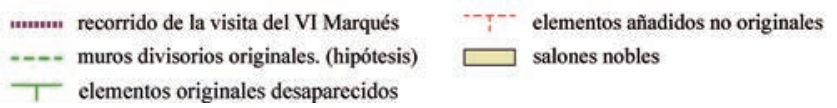

Fig. 1. Itinerario de la visita del VI marqués al castillo de Vélez Blanco. Esquema realizado por Ismael Motos Díaz. 2013. Plano de planta general perteneciente al proyecto de restauración del castillo de Vélez Blanco fase III. 2002. Archivo de la Delegación Territorial de Educación, Cultura y Deporte en Almería, Junta de Andalucía (ADTECD), caja BC-226.

madera, y juntamente el puente, el badizo que está inmediato, y hallose estar de buena calidad y disposición; y no necesita por ahora de reparos ni tampoco las puertas principales, que son de planchas de hierro y embebido en la pared un torno fuerte para levantar el dicho puente levadizo.

Entrose en el primer zaguán, que sirve de cocina, (...) y en el dicho zaguán hay una sala grande baja que está bien parada, a mano derecha como se entra; y otro aposento como se entra a mano izquierda, que también está en buena disposición.

Entrose en el patio principal, donde hay un aljibe, y se reconocieron sus paredes y empedrados y los mármoles (...).

Arch. esp. arte, LXXXVIII, 351, JULIO-SEPTIEMBRE 2015, 223-242

ISSN: 0004-0428, eISSN: 1988-8511, doi: 10.3989/aearte.2015.14 
Subiose luego por la principal escalera, que está edificada de mármoles, y se reconoció le faltan cuatro balaustres, que dijo el portero están quebrados; y subiendo por dicha escalera se entró en el primer cuarto que está al segundo descanso de ella, donde hay tres salas, y todas están buenas. Prosiguiose por dicha escalera y, en lo último de ella, se entró en un cuarto grande donde hay una sala con un retrete y, juntamente, una alcoba con ventanas al dicho patio y al campo. Pasose a la sala del Triunfo" (...).

Según el anterior texto, y como ya afirmó Tapia Garrido², en el ala oeste debían estar las habitaciones íntimas del castillo. Al igual que la escalera principal, éstas gozaban de ventanas ricamente decoradas abiertas al patio. Ambos niveles se encontraban compartimentados, dotados de un cuarto con chimenea y retrete y comunicados por una escalera de servicio anexa a la torre del Homenaje que proveía a las estancias del ala oeste de un acceso secundario desde el patio.

Por el tamaño de las estancias, posición privilegiada con ventanas al patio y al exterior y conexión directa con las salas nobles del ala sur, no hay duda de que las habitaciones del segundo nivel del ala oeste tuvieron que ser los aposentos del Marqués.

Así mismo contamos con la descripción de otros historiadores gracias a los cuales sabemos que el ala sur estaba formada por los salones nobles, entre los que se encontraba la sala de los trabajos de Hércules y la sala de los triunfos de César ${ }^{3}$ también conocidas por la sala de la Mitología y la sala del Triunfo respectivamente. Esta última era la estancia de mayor tamaño y probablemente la más lujosa del palacio en la que el marqués despachaba las visitas de otros nobles o de sus súbditos.

La sala del Triunfo cuenta con dos accesos desde la escalera. El recorrido público sube por completo la escalera hasta la galería alta del patio y desde allí entra a la sala. El otro acceso más privado se realiza a través de la zona de paso de la escalera que comunica la sala del Triunfo con los aposentos del marqués en el ala oeste. Este paso era accesible desde la tercera meseta de la escalera principal a través de una escalera de servicio.

Sin embargo, en la actualidad esta conexión ha sido eliminada. Si las intervenciones de los arquitectos restauradores Francisco Prieto-Moreno y Pardo y Joaquín Prieto-Moreno Ramírez durante las décadas 60 y 70 entendieron y respetaron las circulaciones del espacio de la escalera principal limitándose a desescombrar sin alterar la posición de las piezas originales, las intervenciones de Juan Antonio Molina Serrano y Juan Antonio Sánchez Morales en las décadas de los 80 y 90 priorizaron la musealización del castillo y modificaron el esquema original eliminando la escalera de servicio. La portada-marco de paso fue desmontada, el vano fue cegado y el tramo de la escalera rellenado para crear un almacén accesible desde la zona de paso (fig. 2).

Además, para conectar la escalera con el ala oeste directamente, se construyó una pasarela metálica desde la cuarta meseta, donde se practicó una puerta en el paramento norte antes inexistente.

También fueron desmontados los peldaños originales de mármol blanco que las intervenciones de los anteriores arquitectos restauradores habían respetado y se instalaron unos nuevos modificando las características de la escalera primitiva: morfología de los peldaños, número de escalones por tramo y resolución de encuentros y detalles.

Con el objeto de conocer éstos y otros datos para restituir el espacio de la escalera original, ha sido necesario efectuar el levantamiento planimétrico y tridimensional del estado actual de la estancia. Para ello, he elaborado el croquis y he medido todo el espacio con dispositivos láser. Después, he modelado en tres dimensiones todo el conjunto utilizando programas informáticos de diseño asistido por computadora (CAD). Además, he realizado el levantamiento tridimensional de

\footnotetext{
2 Tapia Garrido, 1959: 175.

${ }^{3}$ Las denominaciones de las salas fueron las empleadas por historiadores a principios del XX en referencia a la temática de las tallas que precisamente coronaban los muros de dichas estancias.
}

Arch. esp. arte, LXXXVIII, 351, JULIO-SEPTIEMBRE 2015, 223-242 ISSN: 0004-0428, eISSN: 1988-8511, doi: 10.3989/aearte.2015.14 

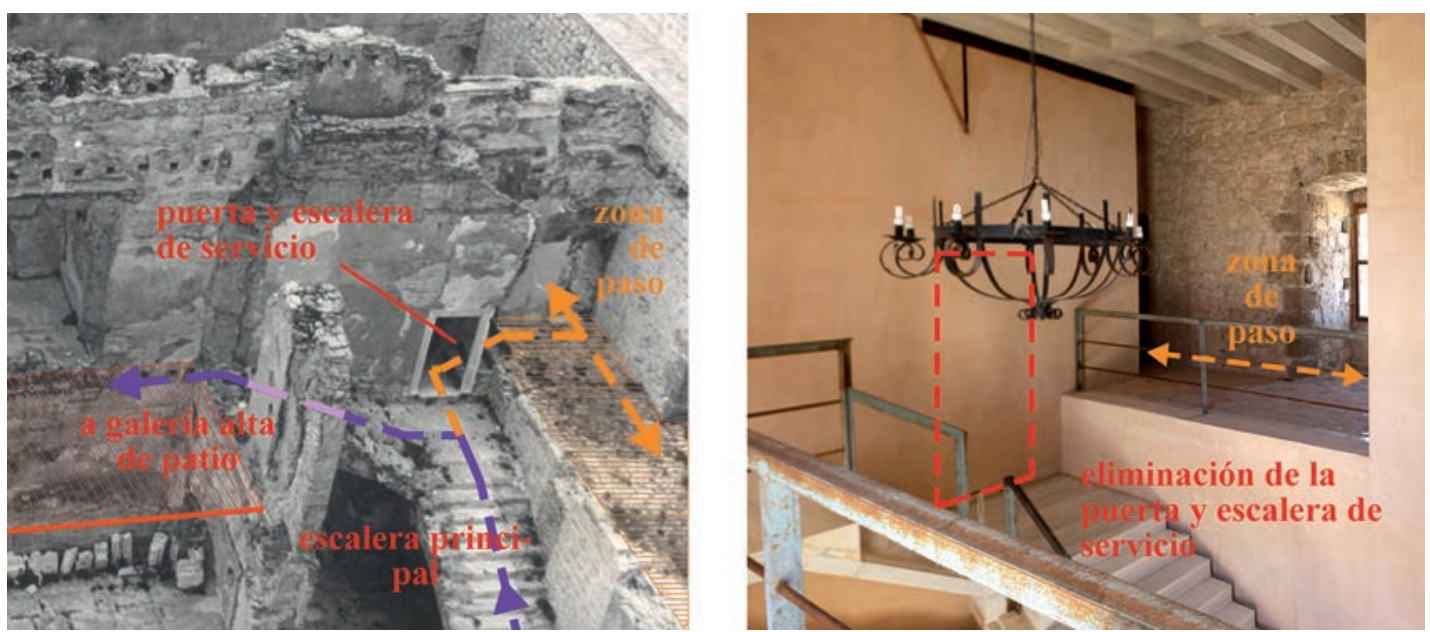

Fig. 2. Transformación de las circulaciones en el espacio de la escalera principal. Imagen izquierda. Circulación original. Fotografía del proyecto de restauración y consolidación del castillo de Vélez Blanco (Almería). Joaquín Prieto-Moreno Ramírez. 1970. AGA.

Imagen derecha. Eliminación de la puerta y escalera de servicio. Fotografía y esquema realizados por Ismael Motos Díaz. 2013.

las piezas de mármol pertenecientes a la escalera que aún se conservan en dependencias del castillo. Para este cometido, he consultado el catálogo efectuado por los arquitectos Molina y Sánchez ${ }^{4}$. Aquellas piezas que no están incluidas en este registro, han sido inventariadas y medidas por mí.

Las herramientas CAD son dispositivos de alta precisión capaces de generar modelos tridimensionales a través de las cuales se puede reconstruir las partes de piezas dañadas, reproducir elementos desaparecidos a partir del estudio morfológico de otros o verificar el montaje de estas piezas sobre el entorno virtual del lugar donde se ubicaban.

A continuación, paso a identificar, analizar y restituir los conjuntos y partes que componían el espacio de la escalera principal y que he clasificado en el elemento escalera (estructura, peldaños, mesetas y balaustrada), la galería, acabados y revestimientos en paredes, suelos y techos, portadas y carpinterías (puertas y ventanas).

\section{El elemento escalera: estructura, peldaños, mesetas y balaustrada}

El elemento escalera cuenta con 4 tramos y 4 mesetas o descansillos. Su estructura, que ha permanecido invariable en el tiempo, está formada por un cuerpo macizo sobre el que descansa el tramo 1 y tres bóvedas de sillares de piedra, cuyo canto e intradós se encuentran en la actualidad al descubierto, en las que apoyan el tramo 2, 3 y 4 . El trazado de las bóvedas de una escalera condiciona las características morfológicas de ésta: longitud del peldaño, pendiente, número de pel-

${ }^{4}$ Catálogo y ordenación de material pétreo de la cornisa de remate del patio del castillo de Vélez Blanco, ADTECD, caja BC-120.

${ }^{5}$ Existe otro catálogo de las piezas elaborado en 2007 por Rosa Morales Sánchez titulado Documentación técnica de elementos pétreos del castillo de Vélez Blanco, Almería, ADTECD, caja B-385.

Arch. esp. arte, LXXXVIII, 351, JULIO-SEPTIEMBRE 2015, 223-242

ISSN: 0004-0428, eISSN: 1988-8511, doi: 10.3989/aearte.2015.14 
daños por tramo, ancho de la huella y contrahuella, etc. Por esta razón, el estudio del levantamiento tridimensional de la estructura ha sido fundamental (fig. 11) pues me ha permitido verificar los resultados que he ido obteniendo a partir de otros documentos.

Para la resolución del número original de peldaños por tramos he recurrido a fotografías incluidas en los proyectos de restauración. En este caso, los planos no han sido concluyentes al ofrecer datos dispares ${ }^{6}$. Según estas imágenes, el número de peldaños de la escalera original es de 29 con 8 peldaños para el tramo 1, 4 peldaños para el tramo 2, 11 peldaños para el tramo 3 y 6 peldaños para el tramo 4. La escalera actual tiene un peldaño más en el tramo 2 y uno menos en el tramo 4.

Para verificar si se trata de una solución correcta, he realizado un replanteo virtual de la escalera a partir del análisis y levantamiento tridimensional de los peldaños originales de mármol que fueron desmontados y que actualmente están almacenados en dependencias del castillo. Aunque hay distintos tipos, el modelo general volumétricamente forma un paralelepípedo achaflanado en casi toda su longitud menos en uno de sus extremos, en el que hay un dado cúbico de menor tamaño. La fotografía siguiente de Leopoldo Torres Balbás es clave para entender la disposición y montaje de los peldaños $^{7}$ (fig. 3). A partir de ésta, he elaborado un esquema tridimensional que simula la colocación de los peldaños de la imagen anterior (fig. 4). Como muestra el esquema, los peldaños van apoyados y solapados uno sobre el otro. A su vez, éstos descansan sobre las bóvedas mediante mortero y relleno. Por esta razón, las piezas se encuentran achaflanadas en su parte posterior. En ambas figuras, podemos apreciar como los extremos cúbicos de las piezas son los que marcan la huella y contrahuella del escalón. Por tanto, consultadas las dimensiones de los peldaños conservados en el castillo, puedo decir que la huella está entre $270-275 \mathrm{~mm}$ y la contrahuella entre 170 $180 \mathrm{~mm}$. Para la restitución virtual he empleado un peldaño tipo con una huella de $275 \mathrm{~mm}$ y una contrahuella de $176 \mathrm{~mm}$ según la cual la altura total que salva este modelo de 29 peldaños es de $5,10 \mathrm{~m}$ (fig. 11). Esta hipótesis queda refrendada al coincidir esta altura resultante de la escalera virtual con la cota original del pavimento de la galería alta del patio del castillo antes de ser desmontado y que he podido conocer a partir de la medición de los elementos del patio instalados en el Museo Metropolitano y considerando las modificaciones acometidas en la reconstrucción.

En la anterior fotografía de Torres Balbás, aparecen las bóvedas de la escalera revestidas en su canto por un aplacado de mármol. En la actualidad, se conservan las piezas que revestían el canto en el tramo 1 y que están situadas en su lugar original aunque los nuevos peldaños no están maclados correctamente sobre éstas.

En relación a la balaustrada, son pocas las referencias escritas que he encontrado. Sabemos gracias a la descripción de Federico de Motos que la escalera contaba con pilastras ricamente esculpidas en las que manos vandálicas causaron graves desperfectos ${ }^{8}$. Joaquín Espín Rael describió la escalera con artística balaustrada de mármol $^{9}$. La documentación gráfica también es escasa. No obstante, de especial valor es el esbozo del marqués de Miraflores que dibuja la balaustrada del tramo 1 y 3 como un conjunto compuesto por una pieza inferior de apoyo y un pasamanos de directriz rectilínea entre los que se intercalan balaustres y la fotografía en posesión de Espín Rael, en el que aparece la silueta del último pedestal de planta alta de la balaustrada ${ }^{10}$.

\footnotetext{
${ }^{6}$ En los planos de los proyectos de restauración consultados coincide que el número de peldaños del tramo 1 es 8 p. y del tramo 3 es 11 p. Sin embargo, los datos divergen para el tramo 2 y 4.

${ }^{7}$ Esta imagen, como veremos en los siguientes apartados, también ha aportado valiosa información para la restitución de otros elementos como el forjado de techo, las portadas y las puertas.

${ }^{8}$ De Motos, 1902.

${ }^{9}$ Espín Rael, 1904a: 135.

${ }^{10}$ Para evitar duplicar estas imágenes, he preferido incluirlas en el apartado de la galería donde aportan mayor información. Ver fig. 6 y fig. 7.
}

Arch. esp. arte, LXXXVIII, 351, JULIO-SEPTIEMBRE 2015, 223-242 ISSN: 0004-0428, eISSN: 1988-8511, doi: 10.3989/aearte.2015.14 


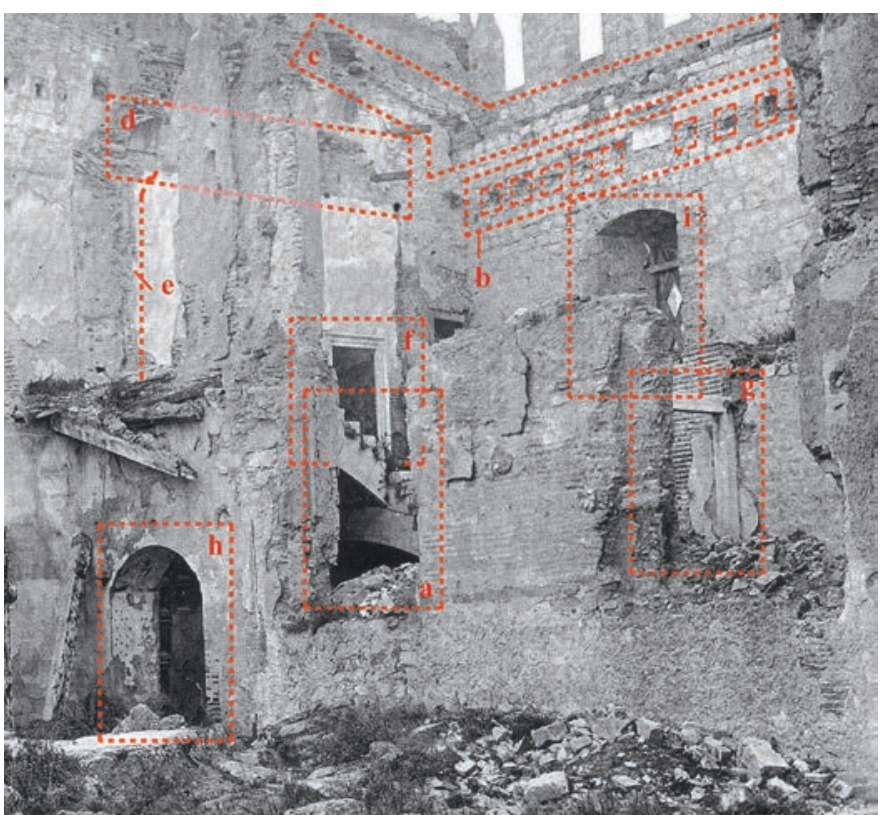

\section{EL ELEMENTO ESCALERA}

a. Disposición de los peldaños del tramo 3 y 4.

\section{TECHO Y CUBIERTA}

b. Oquedades de las vigas de madera del techo.

c. Marcas de la cubierta inclinada.

d. Marcas de una posible faja o friso perimetral entre los muros y el techo.

\section{PORTADAS}

e. Marcas en el muro del conjunto interior de la portada entre la escalera y la galería del patio.

f. Marco de la escalera de servicio.

g. Marco de acceso a las tres salas.

\section{CARPINTERÍAS}

h. Portón entre el zaguán y la escalera.

i. Ventana de la galería.

Fig. 3. Fotografía de Leopoldo Torres Balbás, s.f. Archivo del Patronato de la Alhambra y el Generalife (APAG). F-001290.

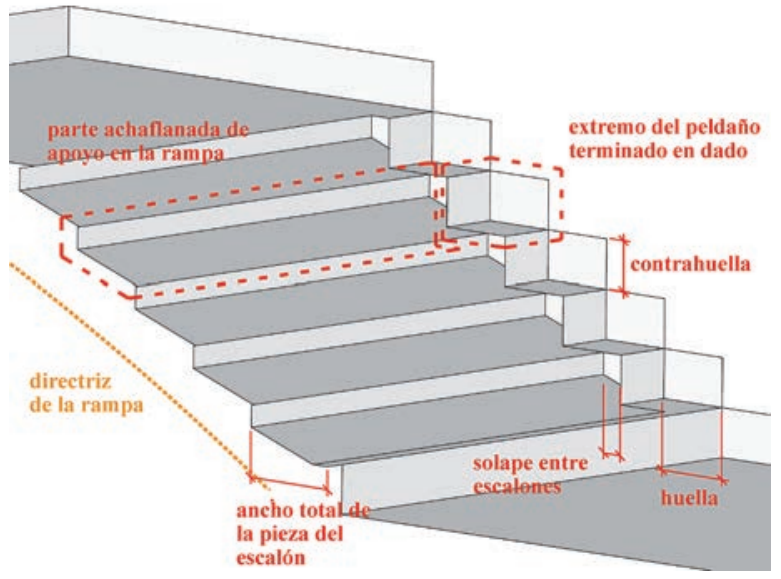

Fig. 4. Montaje virtual de los peldaños del tramo 4 de la escalera. Esquema realizado por Ismael Motos Díaz. C2013.

No obstante, su resolución ha sido posible gracias al levantamiento tridimensional de las piezas que la componían y que se encuentran almacenadas en el castillo. Para entender la función de cada una, poder ubicarlas en su posición original y reproducir las piezas faltantes, he estudiado en paralelo la balaustrada de dos ejemplos coetáneos y también renacentistas: la escalera principal del palacio del marqués de Zenete en la Calahorra y el antepecho del presbiterio de la Capilla Real en Granada. A continuación, expongo los resultados fruto del análisis morfológico comparativo (fig. 5):

Arch. esp. arte, LXXXVIII, 351, JULIO-SEPTIEMBRE 2015, 223-242 ISSN: 0004-0428, eISSN: 1988-8511, doi: 10.3989/aearte.2015.14 

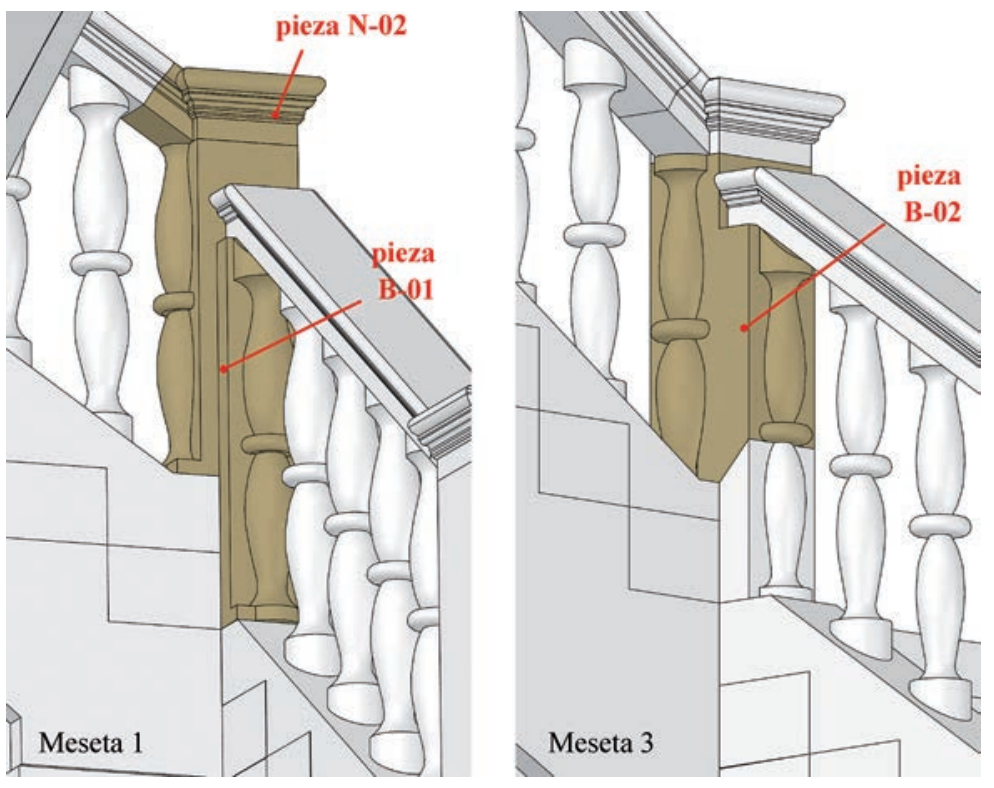

Fig. 5. Restitución del conjunto de la balaustrada a partir de las piezas conservadas en el castillo y del análisis comparativo de la escalera del palacio de la Calahorra y el antepecho del presbiterio de la Capilla Real de Granada. Perspectivas realizadas por Ismael Motos Díaz. (C)2013.

Las piezas B-01 y B-02 son pedestales diseñados para resolver el encuentro en esquina de dos tramos de balaustrada. Tienen esculpidos dos semibalaustres desplazados en la vertical que, al igual que en el palacio de la Calahorra, deben corresponder con la secuencia de balaustres intermedios del tramo inferior y del tramo superior. De hecho, tienen el mismo tamaño, lo cual permite reproducir los balaustres intermedios que "nacen" de los elementos B-01 y B-02.

$\mathrm{La} \mathrm{N}-02$ es una pieza que apoya sobre el pedestal y que funciona como elemento de arranque del pasamanos. La pieza N-02 es compatible con la pieza B-01 y por tanto podría tratarse de dos piezas que originariamente estuvieran juntas. A partir de la medición del plano de arranque de $\mathrm{N}-02$, ha sido posible reproducir el pasamanos incluidas sus molduras. En paralelo a los pasamanos, como en la Calahorra, tuvo que discurrir dos piezas inferiores sobre las que apoyaban los balaustres intermedios. Como no tengo pruebas sobre su forma, aunque probablemente tuvieron una moldura similar e invertida al pasamanos, he decidido modelarlas como un prisma recto.

Analizadas las piezas que integran el conjunto, el siguiente paso es determinar el lugar que ocupan. Para ello, es clave conocer primeramente la ubicación de los pedestales en esquina B-01 y B-02, pues como vimos anteriormente, a partir de esta información puedo reconstruir el resto del conjunto. La respuesta nuevamente está en la escalera de la Calahorra donde he comprobado que la cota de la base del semibalaustre inferior de los pedestales coincide con la cota de la meseta y que la base del semibalaustre superior coincide con la cota del tercer peldaño, o lo que es lo mismo, con el siguiente escalón al que es coplanario. Por tanto, puedo afirmar que el desfase entre los semibalaustres de los pedestales es múltiplo de la altura de la contrahuella del escalón e indica cuántos peldaños hay entre éstos. Esta norma también se cumple en las piezas B-01 y B-02 de Vélez Blanco. Si el desfase de los semibalaustres en la Calahorra es de 3 peldaños, en las piezas B-01 y B-02 es de 2 peldaños.

Según estas premisas y en base a la restitución tridimensional de los peldaños, he llegado a la conclusión de que la pieza B-01 corresponde al pedestal de encuentro de los peldaños del tramo 1 y 2 (meseta 1) y que la B-02 a los del tramo 3 y 4 (meseta 3 ). Ambas resuelven el "salto" de 2 peldaños, no pudiendo pertenecer al encuentro entre el tramo 2 y 3 (meseta 2 ) que es de 3 peldaños. Aún siendo piezas muy parecidas, es seguro que B- 01 pertenece a la meseta 1 y no a la 3 , porque

Arch. esp. arte, LXXXVIII, 351, JULIO-SEPTIEMBRE 2015, 223-242 ISSN: 0004-0428, eISSN: 1988-8511, doi: 10.3989/aearte.2015.14 
los semibalaustres que tiene adosados son de mayor tamaño que los de la pieza B-02 poniendo de manifiesto que en la escalera de Vélez Blanco la altura de los balaustres iban decreciendo sutilmente por tramo.

Según las anteriores deducciones, ésta es la posición de las piezas conservadas en el castillo y la reproducción del resto del conjunto. Ver figura 11.

Se desconoce el paradero del resto de piezas de la balaustrada que fueron reconstruidas en este apartado. Gracias al testimonio de Federico de Motos sabemos que algunas fueron destruidas y robadas antes de la venta ${ }^{11}$. Quizá, como aseguró en 1915 Fernando Palanques, también marcharon para Francia, la más de las ricas pilastras y esculpidos pasamanos que decoraron la regia escalera principal de la feudal mansión, una bella balaustrada del mármol (... $)^{12}$.

\section{La galería}

Aunque otras publicaciones han recogido el esbozo del marqués de Miraflores (fig. 6) y la fotografía de Espín Rael (fig. 7) en los que figura la galería de la escalera principal, éstas no han abordado un estudio sobre su existencia. Es la fotografía de Espín Rael sobre la que parto para afirmar que entre la escalera y la zona de paso que comunica la sala del Triunfo y los aposentos del marqués había una galería formada por 2 arcos sobre 3 semicolumnas que apoyaban en pilastras unidas por un pasamanos y una balaustrada.

El número de arcos y semicolumnas de la galería está corroborado por dos testigos murarios encontrados en fotografías de los proyectos de restauración y que en la actualidad han sido cegados por los revocos empleados en los paramentos (fig. 8). En las imágenes se aprecian tres "pilas" de ladrillo que parecen ser refuerzos sustitutos del "cimiento" original sobre el que descansaban los pedestales y, por tanto, todo el peso del conjunto de mármol y parte del artesonado. La segunda prueba es una piedra de arranque en el muro oeste que coincide con la alineación de la semicolumna central sobre la que probablemente descansara un elemento de arriostramiento del conjunto de la galería.

A partir del levantamiento fotogramétrico de estos testigos y de la imagen de Espín Rael sobre el alzado frontal del estado actual del espacio de la escalera he podido restituir las líneas compositivas del conjunto original. El resultado es que las dimensiones de los vanos y elementos de la galería de la escalera son semejantes a las de la galería del patio, concretamente a los correspondientes con la arcada este (fig. 9).

Por otro lado, si realizamos un análisis en detalle de la imagen de Espín Rael, podemos ver que el intradós del arco se encuentra esculpido y que el capitel está compuesto por un fino ábaco, un ancho collarino y un redondeado baquetón.

Las aparentes características formales del capitel, la curvatura y tallado del arco y las proporciones del conjunto son los datos en que me baso para formular la siguiente hipótesis: el conjunto de arcos y semicolumnas que conformaban la galería de la escalera principal y que aparecen en la anterior fotografía y en el anterior esbozo podría tratarse del conjunto que the Metropolitan $\mathrm{Mu}-$ seum of Art (en adelante MET) propuso para ser intercambiado por fragmentos de la cornisa del patio que no fueron extraídos del castillo en 1904 (fig. 10). Esta información está basada en el documento Proposed exchange of architectural elements from the castle of Velez Blanco for the missing pieces of cornice that still remain at Vélez (Propuesta de intercambio de elementos arquitectónicos del castillo de Vélez Blanco por las piezas faltantes de la cornisa que todavía permanecen

\footnotetext{
${ }^{11}$ De Motos, 1902.

${ }^{12}$ Lentisco Puche, 2007: 146-155.
}

Arch. esp. arte, LXXXVIII, 351, JULIO-SEPTIEMBRE 2015, 223-242

ISSN: 0004-0428, eISSN: 1988-8511, doi: 10.3989/aearte.2015.14 


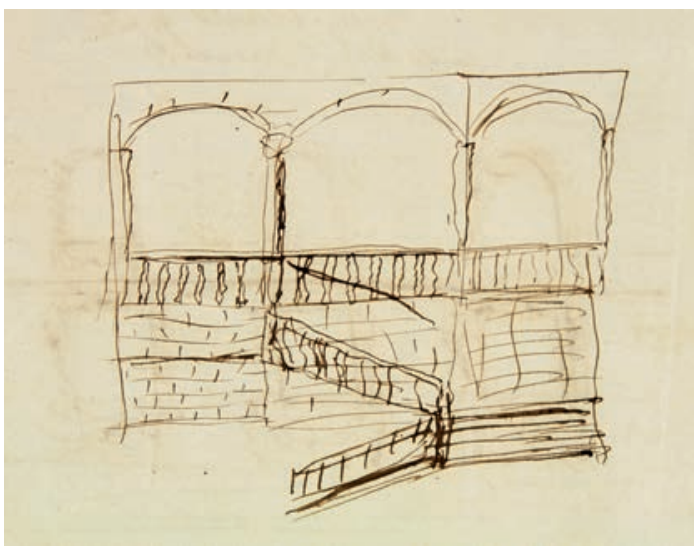

Fig. 6. Esbozo de la escalera principal realizado por el marqués de Miraflores, 1859. Archivo General de la Fundación Casa Medina Sidonia, leg. 6282.

Fig. 7. Imagen en la que aparece un pedestal, el pasamanos, una semicolumna, un capitel y un arco pertenecientes al conjunto de la galería de la escalera principal. Joaquín Espín Rael. h. 1900. Fondo Cultural Espín (FCE). Fundación Caja Mediterráneo.

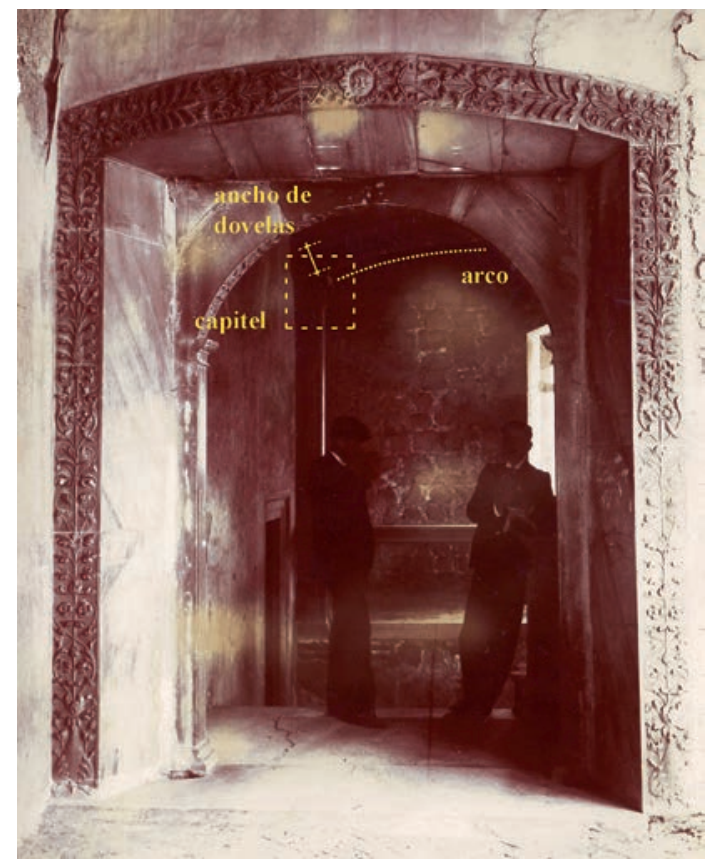

en Vélez) $)^{13}$. El objetivo de la petición era recuperar los fragmentos de la cornisa sitos en Vélez Blanco y que Olga Raggio, la por entonces comisaria de escultura europea y artes decorativas del museo, reconoció en su visita a la villa en la primavera de 1959.

He podido analizar las dimensiones del conjunto del MET gracias a que estuvo instalado en la meseta intermedia de la escalera entre la segunda y tercera planta de la casa de Blumenthal y a que antes de su demolición estas piezas fueron numeradas y medidas por encargo del museo ${ }^{14}$. Según esta documentación, el conjunto contaría con unas dimensiones sensiblemente inferiores a las estimadas en este estudio para el conjunto de la galería de la escalera en Vélez Blanco. Cierto es que en fotografías de la casa de Blumenthal se aprecia que las piezas de arranque de los arcos son de menor tamaño que las de los arcos ofrecidos por el MET, lo cual indica que el conjunto pudo ser reducido para su adaptación al ámbito de la escalera de la mansión.

Desafortunadamente, la definición de la fotografía de Espín Rael no permite confirmar que los capiteles y fustes del conjunto de la escalera en Vélez Blanco sean los capiteles jónicos y los fustes de sección semicircular incluidos en el intercambio propuesto por el MET. Por tanto, no hay

${ }^{13}$ Archivo General de la Administración (AGA), IDD (03)000.000, caja 65/00246. Este documento lo estudio en detalle en el artículo que escribí para la revista ph investigación del Instituto Andaluz del Patrimonio Histórico y que tiene por título "La propuesta del Metropolitan Museum of Art de intercambio de elementos arquitectónicos del castillo de Vélez Blanco en 1963” en http://www.iaph.es/phinvestigacion/index.php/phinvestigacion/article/view/42. Este texto analiza los distintos agentes y organismos españoles que emitieron un dictamen desfavorable (no todos) gracias a los cuales la propuesta fue rechazada y la cornisa pudo ser restituida en el patio del castillo de Vélez Blanco en los posteriores proyectos de restauración.

14 Barlow-Meagher, 1945. 


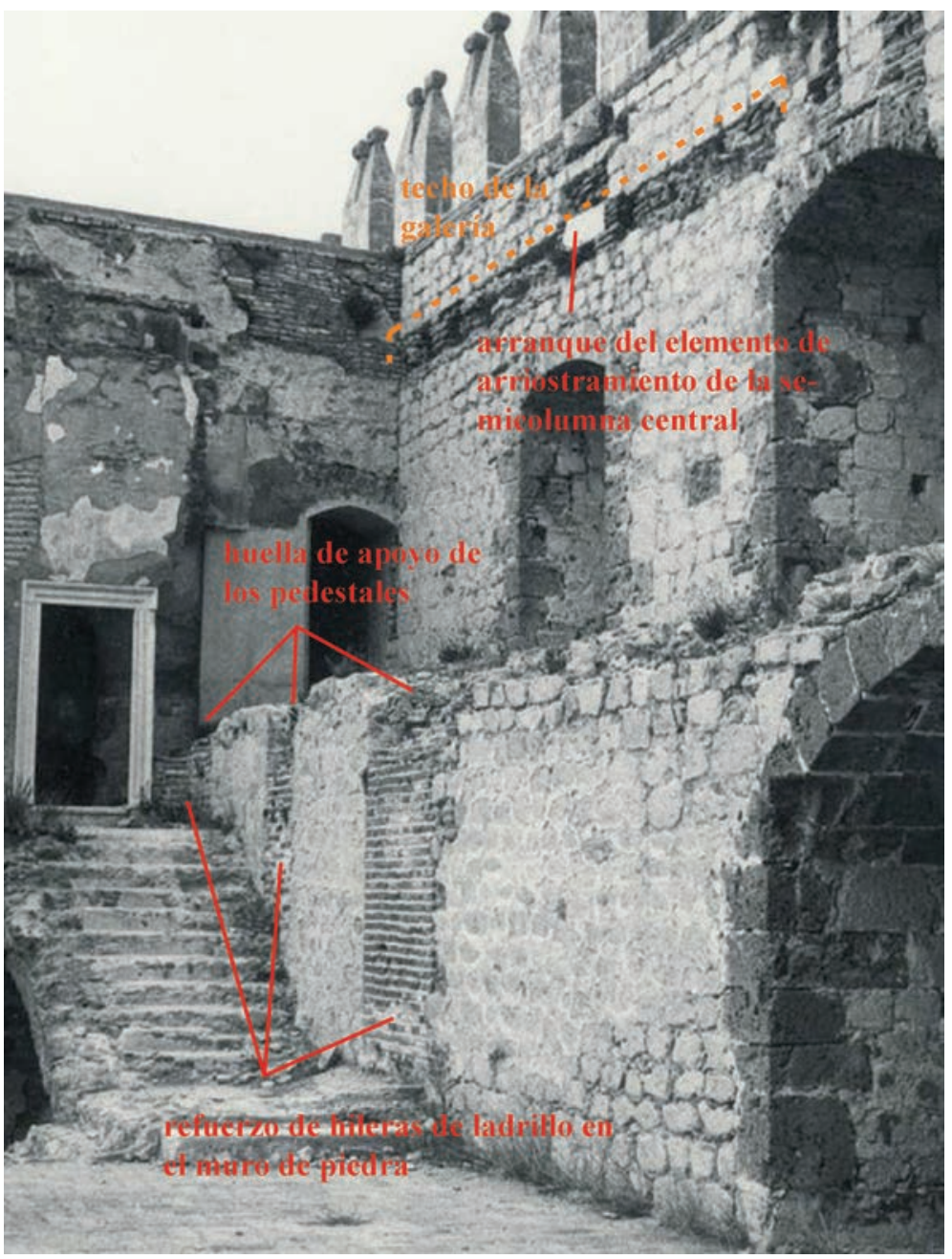

Fig. 8. Refuerzos en el muro, huellas de apoyo de los pedestales y arranque del elemento de arriostramiento de la semicolumna central. Fotografía del proyecto de obras de consolidación y restauración del castillo de Vélez Blanco (Almería). 1979. AGA.

que descartar que el conjunto original pudiera estar formado por otros capiteles y fustes que también tendrían las proporciones de la arcada superior del patio según he demostrado en el presente artículo.

En esta línea cabe plantear una segunda hipótesis que a continuación expongo:

He identificado en la casa de Blumenthal 14 semicolumnas ${ }^{15}$ que responden a la tipología de la galería alta del patio en Vélez Blanco: 12 de ellas fueron instaladas en la nueva versión del patio distribuidas en 3 flancos $(4+4+4)$ y las otras 2 fueron empleadas en la arcada de arranque de la escalera en la planta segunda. Sin embargo, el patio en Vélez Blanco originariamente, al igual que en la instalación actual en el MET, contaba con 11 semicolumnas en 2 flancos (5+6). Por tanto, la diferencia puede estar en las tres semicolumnas de la galería de la escalera. Según esta teoría, Blumenthal recibió 14 semicolumnas de igual tipología que procedían 11 del patio y 3 de la galería de la escalera

${ }^{15}$ Sin contar las semicolumnas compuestas de encuentro entre arcadas.

Arch. esp. arte, LXXXVIII, 351, JULIO-SEPTIEMBRE 2015, 223-242

ISSN: 0004-0428, eISSN: 1988-8511, doi: 10.3989/aearte.2015.14 


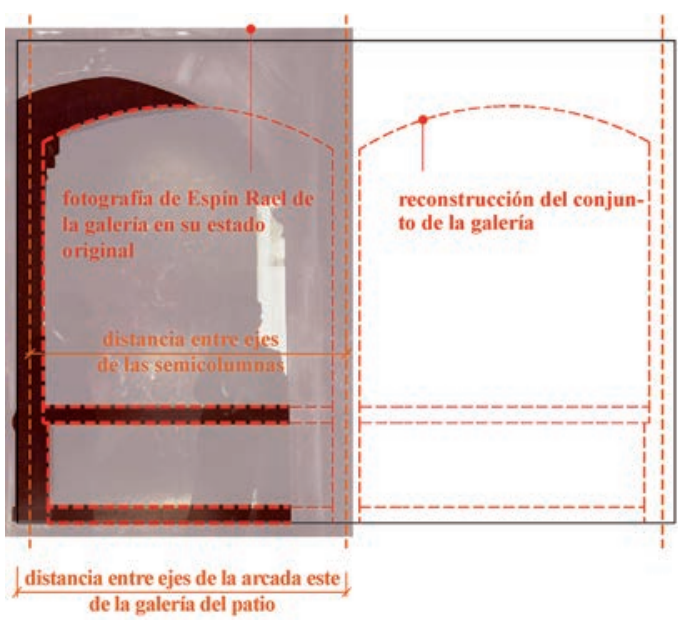

a. Base de la pilastra. Pieza conservada en Vélez Blanco.

b. Parte inferior de la balaustrada. Piezas conservadas en Vélez Blanco.

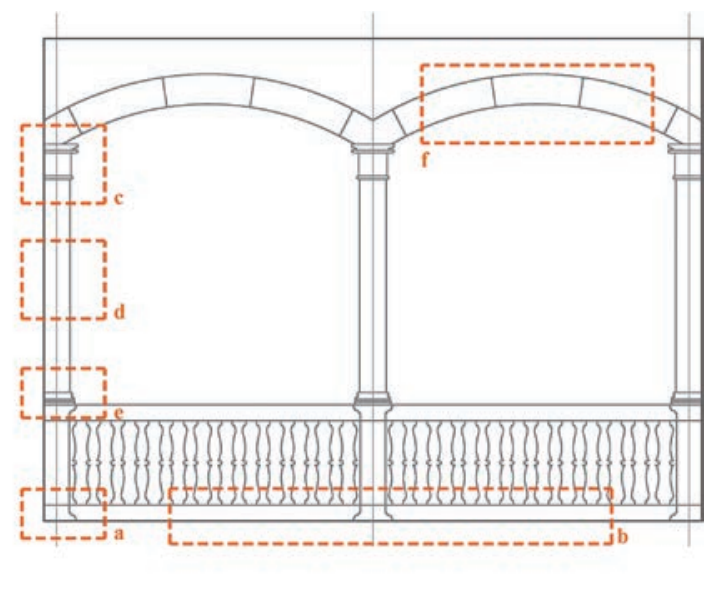

c. Capitel. Restitución volumétrica aproximada según foto de Espín Rael.

d. Fuste. Restitución según conjuntos del MET.

e. Basa. Restitución según conjuntos del MET.

f. Dovelas. Despiece según conjuntos del MET.

Fig. 9. Restitución compositiva de la galería y de sus elementos arquitectónicos.

Esquema realizado por Ismael Motos Díaz. (C) 2013

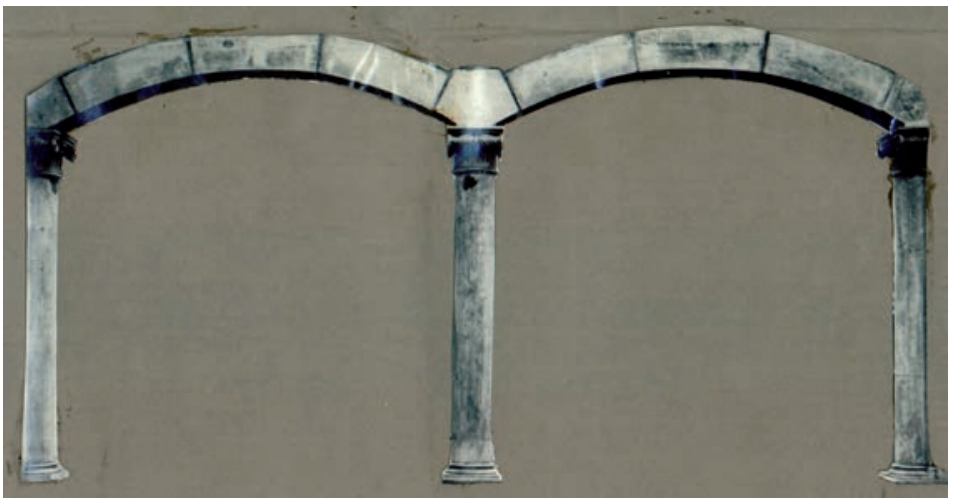

Fig. 10. Conjunto escultórico propuesto para el intercambio del MET. AGA.

en Vélez Blanco. Para la construcción de su casa aprovechó indistintamente 12 para ampliar el número de semicolumnas del patio y 2 para componer el conjunto del arranque de la escalera ${ }^{16}$.

Para la restitución en detalle de cada elemento arquitectónico del conjunto he recurrido a diversas fuentes. He colocado en su posición original aquellas piezas de la galería conservadas en el castillo que he catalogado y modelado en tres dimensiones. Otros componentes homólogos de-

${ }^{16}$ Hay que aclarar que algunos de los fustes de las susodichas semicolumnas instaladas en la casa de Blumenthal y en el MET son reproducciones. En la actualidad, en el castillo se almacenan cinco fragmentos de fustes que pudieron ser descartados por su estado de fragmentación o porque pudieron ser extraídos del castillo antes de la venta.

Arch. esp. arte, LXXXVIII, 351, JULIO-SEPTIEMBRE 2015, 223-242 ISSN: 0004-0428, eISSN: 1988-8511, doi: 10.3989/aearte.2015.14 
saparecidos han sido reconstruidos a partir de éstas. El capitel, el fuste y la basa de las semicolumnas han sido restituidas a partir de la imagen de Espín Rael y los conjuntos del MET.

Para avanzar en esta investigación es necesario acceder, medir y analizar las piezas procedentes del castillo de Vélez Blanco que fueron donadas por Blumenthal y que no se encuentran expuestas al público en el MET. Desgraciadamente, la solicitud no ha sido aún aceptada a fecha de entrega de este trabajo.

Para finalizar, demostrado que la galería de la escalera estaba formada por dos arcos es necesario aclarar por qué el esbozo realizado por el marqués de Miraflores (fig. 6) parece indicar la existencia de tres. En este bosquejo el marqués dibujó primeramente los peldaños de la escalera y la balaustrada. Después dibujó los dos arcos de la galería de la escalera que corresponden con el arco izquierdo y central del esbozo. A continuación, trazó una línea vertical que separan los anteriores elementos del arco derecho. Esta línea está indicando un cambio de plano del alzado pues tanto el vano derecho como la ventana cuadrada que está dibujada debajo de éste corresponden con la ventana superior e inferior del patio que están ubicadas en el paramento opuesto.

Gracias a este texto, ahora es más fácil entender la descripción que realiza Sebastián de Miñano en su Diccionario redactado en la década de los 20. En él afirma que los arcos del patio están primorosamente trabajados y llenos de bajos relieves, como también lo están los adornos que tienen seis ventanas y dos puertas y la escalera principal, que también es de la misma piedra ${ }^{17}$. Estos motivos se refieren a las pilastras, capiteles, intradós de los arcos y paneles que embellecieron el espacio de la escalera. Restitución de la galería (fig. 11).

\section{Acabados y revestimientos en paredes, suelo y techo}

No hay muchas evidencias que me permitan precisar cómo eran los acabados y revestimientos en paredes, suelo y techo del espacio de la escalera. En la actualidad, solamente se conserva el suelo de piedra caliza primitivo de la planta baja. Por eso, he comenzado buscando en la documentación escrita referencias sobre la decoración general del palacio para tratar de imaginar las cualidades de este espacio. En 1769, el X marqués describe las estancias con preciosos mármoles, artesonados y tallas en las salas ${ }^{18}$. También en el siglo XVIII, Antonio José Navarro López detalla: "la habitación es alegre, con bellos miradores y grandes salas. No se conserva pintura alguna, pero todavía se ven relieves alusivos a las batallas y victorias de los Fajardos (...)"19.

Además de apreciar los frisos de la sala del Triunfo y de la Mitología que posteriormente otros autores describirán, esta cita podría insinuar que las paredes originariamente pudieron estar pintadas artísticamente. Una carta firmada por Luis Meléndez de Guzmán fechada el 23 de junio de 1648 es la prueba de que las paredes de las estancias fueron pintadas de blanco durante intervenciones de restauración realizadas en el castillo ${ }^{20}$. No cuento con información sobre las pinturas habidas anteriores a este momento. Sí está documentado que las salas anteriormente mencionadas estaban decoradas con 6 paños de tapices cada una que fueron en 1607 desmontados de su ubicación original y enviados a Valladolid por el IV marqués al palacio de su padrastro y padre político, don Juan Alfonso Pimentel ${ }^{21}$. Desconozco si las paredes de la escalera también estaban cubiertas con tapices. Federico de Motos hace mención a los magníficos artesonados, frisos y zócalos del palacio.

\footnotetext{
${ }^{17}$ De Miñano, 1826: 276.

${ }^{18}$ Díaz López, Lentisco Puche, 2006: 90.

${ }^{19}$ Navarro, Castillo Fernández, 2000: 74.

20 Archivo General de la Fundación Casa Medina Sidonia (AGFCMS), leg. 1.307; BLANC, 1999.

${ }^{21}$ AGFCMS, leg. 1.657; Nicolás Martínez, 2011: 76.
}

Arch. esp. arte, LXXXVIII, 351, JULIO-SEPTIEMBRE 2015, 223-242

ISSN: 0004-0428, eISSN: 1988-8511, doi: 10.3989/aearte.2015.14 


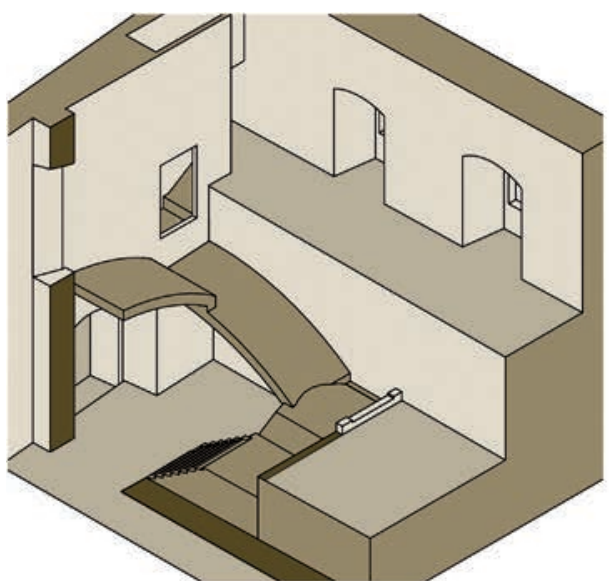

Estado actual. Levantamiento tridimensional de los muros y las bóvedas de la escalera.

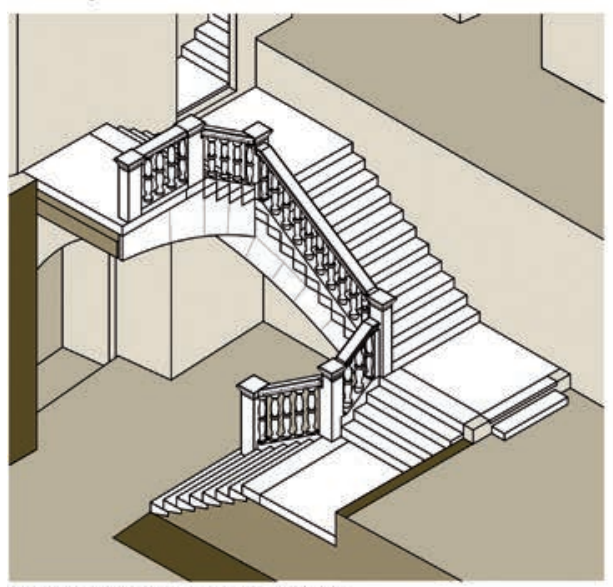

Restitución de la balaustrada.

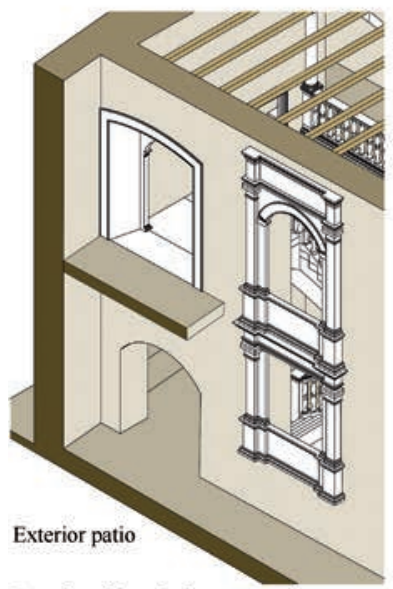

Restitución de las portadas y carpinterías.

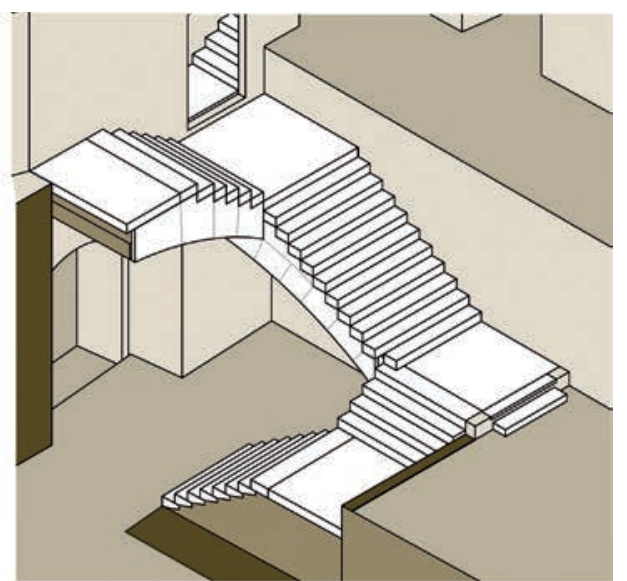

Restitución de los peldaños y las mesetas.

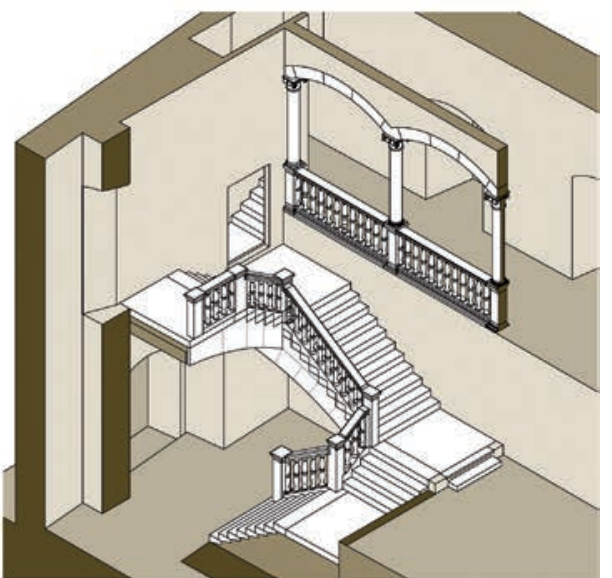

Restitución de la galería.

Fig. 11. Restitución tridimensional de cada una de las partes que conformaron el espacio de la escalera principal. Perspectivas axonométricas realizadas por Ismael Motos Díaz. (C2013.

Arch. esp. arte, LXXXVIII, 351, JULIO-SEPTIEMBRE 2015, 223-242 ISSN: 0004-0428, eISSN: 1988-8511, doi: 10.3989/aearte.2015.14 
También Espín Rael manifestó la importancia de este castillo, en el que los mármoles, los azulejos granadinos y las maderas talladas de sus techos y puertas constituian una joya de incalculable valor $^{22}$. Otros historiadores repetirán estas descripciones realizando pocas aportaciones extras.

Como comenté anteriormente, en la actualidad se conserva el pavimento original de la planta baja de la escalera. Se trata de un pavimento formado por piezas de piedra caliza que cuenta con un despiece irregular de bloques rectangulares. Las piezas se encuentran en buen estado de conservación, aunque están redondeadas y picadas a causa de la abrasión. El pavimento de la galería de la escalera estaba formado por baldosas cerámicas contrapeadas e intercaladas con olambrillas vidriadas, de iguales características al paño que se conserva en la estancia de la planta alta del ala oeste (fig. 2).

Respecto a los azulejos sitos en el espacio de la escalera, contamos con la siguiente descripción publicada por Espín Rael en 1904: "esta escalera, con artística balaustrada de mármol, tenía su intradós y zócalo revestido de azulejos de adorno rehundido o cuenca de vivos colores con entonaciones metálicas y del mismo gusto plateresco que imperaba en la ornamentación de todo este alcázar" ${ }^{\prime 23}$.

Esta tipo de azulejo no parece corresponder con las características de los pocos fragmentos que aún permanecen en el castillo y en el museo Miguel Guirao de Vélez Rubio. Encontrar cuáles fueron los azulejos originales que pudieron embellecer los zócalos y el intradós de la escalera es una tarea de elevada complejidad que no debo abordar en este trabajo por la envergadura que esta labor tendría en relación al objetivo perseguido.

Respecto al techo y cubierta que cubría el espacio de la escalera, he podido conocer algunos detalles a partir de la fotografía de los años 20 de Torres Balbás (fig. 3).

En el margen derecho de la imagen, lienzo oeste de la escalera, se aprecian las oquedades en las que empotraban las vigas del techo. La ausencia de este tipo de marcas en el muro perpendicular sur, hace pensar que la solución de cubrición pudiera ser la de un forjado plano unidireccional de vigas de madera de sección rectangular dispuestas en dirección este-oeste. Sobre él, aparecen las marcas de una cubierta inclinada que estaba rematada por planchas de plomo ${ }^{24}$. Éstas resolvían la evacuación de aguas pluviales.

La solución de vigas planas de madera coincidiría con la empleada en las galerías del patio, la cual pertenece a la tradición gótica española. En la instalación del patio en el MET, se han dispuesto entre las vigas de las galería alta azulejos a dos por tabla cuya procedencia se desconoce. Este sistema decorativo lo encontramos en edificios coetáneos al castillo como la iglesia de Alcalá del Río, el Convento de Santa Clara y la Casa de Pilatos en Sevilla ${ }^{25}$. No cuento con pruebas para saber si el techo original pudo tener o no azulejos aunque es de extrañar que no fuera descrito por los historiadores que lo conocieron. Tampoco sé si estas vigas pudieron ser parte de un artesonado de madera con características comunes al que tuvo otras dependencias del palacio ${ }^{26}$ o semejantes a los conservados en las estancias del palacio de la Calahorra.

Es posible que el encuentro entre el techo y el muro estuviera resuelto por una faja o friso perimetral de madera. La prueba que lo demostraría es que en la fotografía de la figura 3 se aprecia una marca bajo el forjado de ancho parecido. Este cuerpo pudo ocupar todo el perímetro de la sala pasando por encima del conjunto de la galería de la escalera.

22 Espín Rael, 1904b: 101.

${ }^{23}$ Espín Rael, 1904a: 135.

${ }^{24}$ Nicolás Martínez, 1995: 203-211.

${ }^{25}$ Raggio, 1964: 237.

${ }^{26}$ Ver fig. 49 Detalle de un artesonado de madera procedente de Vélez Blanco en Raggio, 1964: 173. (No ha sido incluida por reducir el número de figuras del artículo).

Arch. esp. arte, LXXXVIII, 351, JULIO-SEPTIEMBRE 2015, 223-242

ISSN: 0004-0428, eISSN: 1988-8511, doi: 10.3989/aearte.2015.14 
Desconozco si pudo contar con molduras o bajorrelieves como los frisos de los triunfos de César y de los trabajos de Hércules. Nuevamente, estimo que si así hubiera sido, hubiese sido descrito por otros autores.

En conclusión, aunque desconozco con absoluta exactitud cuáles eran los acabados y revestimientos en paredes y techos del espacio de la escalera principal, sí he lanzado algunas reflexiones e hipótesis que me permiten acercarme al objetivo de este trabajo: recrear las cualidades espaciales, lumínicas y materiales de este ámbito y simular la experiencia perceptiva vivida en el siglo XVI.

\section{Portadas}

Federico de Motos en 1902, fecha anterior a la venta de los más valiosos bienes del palacio, describe que atravesando una suntuosa portada (desde la escalera), se entra en la galería alta (de patio), en donde se admira otra portada de mármol del más puro Renacimiento, que da acceso al salón llamado del Triunfo ${ }^{27}$.

En la actualidad, ambas portadas se encuentran instaladas en el MET. La portada de acceso a la sala del Triunfo está montada en la planta baja de la instalación del patio y decora la puerta de acceso a la biblioteca Thomas J. Watson Library, sita en el propio museo.

Para identificar la portada ubicada originariamente entre la escalera principal y la galería alta del patio, es preciso contar nuevamente con la fotografía de Joaquín Espín Rael (fig. 7). En ésta se aprecia que la portada cuenta en realidad con un conjunto distinto por cada cara. Por ello y para una mayor claridad en la exposición, he diferenciado entre el conjunto exterior (cara hacia la galería) y el conjunto interior (cara hacia la escalera) de la portada. En la actualidad, el conjunto exterior de la portada está instalado en el MET en el acceso de planta baja al patio.

Por otro lado, en la imagen de Espín Rael sólo se aprecia la parte posterior y el vano de paso del conjunto interior que está formado por un arco esculpido en su intradós con motivos vegetales soportado por 2 pilastras adosadas de mármol. Éste corresponde con la portada del balcón instalada en el patio del MET que Olga Raggio afirmó que perteneció a Vélez Blanco sin identificar a qué parte del palacio y que Federico de Motos cita en su publicación como suntuosa portada. He verificado mediante fotogrametría que los vanos entre la portada del balcón y el conjunto interior de la portada de la escalera en la fotografía coinciden. Asimismo, existen otras pruebas que lo confirman. Como muestra la figura 3, el perfil derecho de la portada del balcón coincide con las marcas en el muro sobre el que estaba adosado el conjunto interior. Además, éste guarda relación compositiva con el cuerpo superior de ventanas del mismo alzado del patio.

Respecto a las dos ventanas situadas en el espacio de la escalera que abren al patio, sabemos que en su cara exterior estuvieron enmarcadas por bellas tallas de mármol al igual que las otras cuatro ventanas que conformaban el alzado oeste del patio hoy instalado en el MET. Sin embargo, sólo cuento con el esbozo del marqués de Miraflores (fig. 6) para conocer cómo eran los huecos y cuerpos de las ventanas en su cara interior. En el bosquejo, el autor dibuja la ventana superior con características semejantes a la portada interior entre la escalera y la galería alta de patio sólo que añade con trazo de menor intensidad un peto con balaustres igual al de la galería. Este diseño se asemejaría al antepecho esculpido con balaustres semiempotrados que fue instalado en la escalera entre la planta 1 y 2 en la casa de Blumenthal ${ }^{28}$. Estas piezas no se encuentran expuestas al público en el MET. Será necesario encontrar nueva documentación o conocer su paradero para poder avanzar en estas cuestiones.

\footnotetext{
${ }^{27}$ De Motos, 1902.

${ }^{28}$ Barlow-Meagher, 1945.
} 
En relación a las portadas de paso entre la escalera y otras dependencias anexas, he comprobado gracias a la fotografía de Torres Balbás (fig. 3), que tanto el marco de la escalera de servicio y el de acceso a las tres salas se almacenan en dependencias del castillo.

Como veremos en el siguiente apartado carpinterías: puertas y ventanas, el arco de paso entre el zaguán y el espacio de la escalera contaba en su cara norte con un gran portón. Por tanto, en el paramento de la escalera no pudo haber portada. Respecto al vano de acceso al patio, según una acuarela del mismo realizada antes de ser desmontado y que se conserva en the Hispanic Society of America ${ }^{29}$, no estuvo revestido con ningún cuerpo escultórico.

Por último, desconozco cómo era el vano de acceso a las dependencias del marqués del ala oeste. No encontré rastro documental que me permita conocer qué dimensiones tenía, si contaba con portada o cómo era la puerta de ingreso. Restitución de las portadas (fig. 11).

\section{Carpinterías: puertas y ventanas}

Según la descripción del castillo recogida en Monumentos Españoles. Catálogo de los declarados histórico-artísticos (1944-1953) las puertas eran de nogal tallado al igual que los artesonados. También sabemos por la visita del VI marqués en 1567 que algunas puertas y ventanas ya se encontraban en mal estado y que necesitaban ser reparadas. El documento que aporta más información sobre las carpinterías del espacio de la escalera es la fotografía de Leopoldo Torres Balbás (fig. 3). En ella, se aprecia claramente como el zaguán y la escalera estaban separados por un gran portón de casetones cuadrados rehundidos sobre el que se practicaba una puerta de menor tamaño. También puede apreciarse parcialmente que el hueco de la ventana de la galería hacia poniente estaba protegido por otra carpintería de estructura moldurada romboidal. En la imagen parece que algunos de estos rombos estaban cegados y otros podrían contar con un paño transparente y/o translucido. Toda ella está fija al muro gracias a dos traviesas de madera que se empotraban en los laterales. Aún se conservan los orificios donde se introducían. Del portón también se conservan los orificios en el suelo y los elementos de anclaje del eje de giro que se encuentran en su margen derecho.

Según este análisis he restituido las piezas retratadas en la fotografía que considero pudieran ser las piezas originales (fig. 11).

La fotografía de Torres Balbás no es el único documento que aporta información sobre las carpinterías del castillo. La puerta de acceso a la sala de los trabajos de Hércules fue descrita por Federico de Motos en 1902: "Por este salón, y atravesando una puerta de tableros blasonados, se penetra en otra estancia de más reducidas dimensiones, y si cabe más bella, ostentando un buen artesonado floreado y un friso de un metro de ancho, en donde magistralmente se reproducen los doce trabajos de Hércules (...)"30.

El hecho de que de Motos no describa otras puertas y ventanas, hace pensar que muchas de ellas pudieron ser extraídas del castillo antes de la venta de 1903.

En el caso de la puerta de acceso desde la segunda meseta de la escalera a las tres salas del ala oeste, conozco sus dimensiones gracias a las muecas del marco de mármol restituido en el apartado anterior sobre el que cerraba. Al no tener más detalle, la he modelado como un simple paralelepípedo (fig. 11).

De la puerta de paso entre la escalera y la galería alta del patio, por los orificios practicados en el suelo y en el dintel (fig. 7), sé que estaba formada por dos hojas que cerradas quedaban adosaban al arco de medio punto y que abiertas abatían sobre las propias jambas.

${ }^{29}$ Ver fig. 5 Boceto en acuarela que muestra una vista ideal del patio antes de ser sustraído del castillo en 1904 en Raggio, 1964: 145.

${ }^{30}$ De Motos, 1902. La puerta descrita por de Motos, podría tratarse de la puerta también blasonada que fue fotografiada y publicada por Espín Rael (Espín Rael, 1904a).

Arch. esp. arte, LXXXVIII, 351, JULIO-SEPTIEMBRE 2015, 223-242

ISSN: 0004-0428, eISSN: 1988-8511, doi: 10.3989/aearte.2015.14 
Según la acuarela de the Hispanic Society of America, el paso entre la planta baja de la escalera y el patio estaba separado por una puerta de igual silueta que el vano, el cual estaba rematado por un arco de medio punto. Ésta tenía apertura hacia el patio.

Por último, señalar que con la información que dispongo desconozco cómo eran las carpinterías de las ventanas de la escalera que abrían al patio. Según el boceto del marqués de Miraflores la ventana inferior estaría formada por dos hojas de tableros rectangulares.

\section{Restitución infográfica}

Una vez modeladas tridimensionalmente las distintas partes y conjuntos del espacio de la escalera, he elaborado varias imágenes virtuales del estado original mediante un programa informático de creación de infografías fotorealistas. Los programas de diseño asistido por ordenador que he utilizado son dispositivos muy útiles para la investigación en el campo del patrimonio arquitectónico. Pero sin duda, vuelvo a señalar, la complejidad de este trabajo no está en el uso de estos medios sino en formular las preguntas adecuadas y resolverlas mediante el análisis histórico-documental.

A continuación, aclaro cuál ha sido el criterio para la restitución de algunos elementos que no han sido especificados anteriormente:

- El suelo de planta baja ha sido restituido a partir del pavimento original de piedra caliza.

- El suelo de la galería de la escalera ha sido restituido a partir del único pavimento de iguales características conservado en el castillo y que se encuentra en la planta alta del ala oeste. Las olambrillas han sido reproducidas sin figura, pues desconozco cuáles eran exactamente.

- Desconocemos cómo eran las paredes originales pero sí sabemos que fueron pintadas en blanco en el siglo XVII. Por tanto, se empleará este color para la restitución por tratarse de la referencia conocida más antigua.

- Respecto a la restitución de los zócalos de azulejos, con la poca información que dispongo es inevitable "suponer" algunas cuestiones para transmitir sus sensaciones. He considerado según el esbozo del marqués de Miraflores que los paños del zócalo corresponden con el paramento oeste de la escalera. He simulado el despiece y sus cualidades metálicas, tal y como describió Espín Rael. Igual tratamiento he utilizado para el intradós de la escalera.

- He restituido las vigas de madera del techo a partir de las fotografías anteriores definiendo su tamaño, número e intereje basándome en los orificios de empotramiento del muro. Sin la certeza de que el techo tuviera azulejos o artesonado, he recurrido al modelo más simple y que corresponde con el techo de la galería del patio: acabado de enfoscado blanco.

- Como desconozco la existencia o cómo era la faja o friso perimetral entre los muros y techo, he preferido omitirla.

- He restituido el conjunto interior de la portada entre la escalera y la galería alta del patio a partir de Barlow-Meagher, 1945.

- En relación a la balaustrada, como ya mencioné, no cuento con información para conocer con precisión cómo eran las piezas inferiores sobre las que apoyaban los balaustres intermedios. Aunque probablemente tuvieron una moldura similar e invertida al pasamanos, he decidido modelarlas como un prisma recto. Tampoco cuento con información para determinar exactamente cuál era la distancia entre los balaustres de cada tramo. Se ha estimado utilizando como referencia el intereje de la balaustrada de la galería que he podido conocer gracias a las marcas encontradas en las piezas de apoyo inferiores que se almacenan en el castillo. Desconozco cómo eran los pedestales que apoyaban en la última meseta y por tanto desconozco cómo era el detalle de encuentro del pasamanos entre ésta y el tramo 3. Se ha restituido con una solución que resuelve el encuentro entre cada una de las partes. 
A continuación, se adjunta una imagen infográfica del estado original obtenida a partir de las hipótesis y demostraciones desarrolladas en esta investigación: fig. 12. El lector podrá consultar más imágenes del estado original en www.ismaelmotos.com

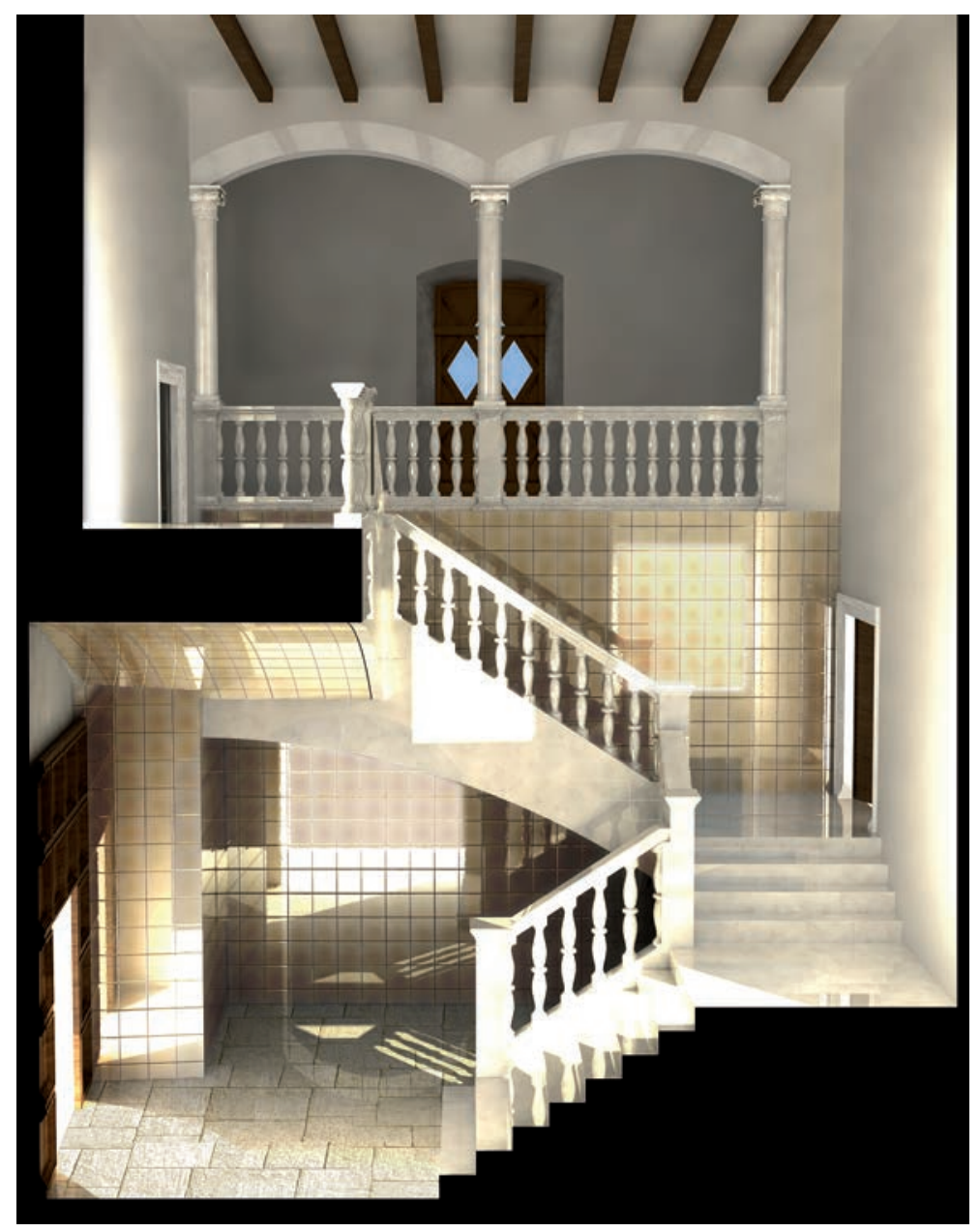

Fig. 12. Alzado oeste. Imagen infográfica del estado original del espacio de la escalera principal. Imagen realizada por Ismael Motos Díaz. (C2013.

\section{Agradecimientos: a mis padres Manuel y Cándida}

Los arquitectos del Plan Director del castillo de Vélez Blanco, Pedro Salmerón Escobar y Diego Garzón Osuna, han acometido labores de investigación sobre el espacio de la escalera para la redacción del proyecto de Habilitación para la visita pública de las salas nobles del castillo de los Marqueses de los Vélez (2010). No he podido analizar ni incluir referencias sobre este documento pues no está disponible para consulta al encontrarse en proceso de revisión por parte de la Delegación Territorial de Educación, Cultura y Deporte de Almería. Sin embargo, he mantenido contacto con los autores quienes me han ayudado al inicio de esta investigación. Por ello, quiero agradecer su generosa colaboración y desear que este artículo sirva de apoyo a sus trabajos.

Arch. esp. arte, LXXXVIII, 351, JULIO-SEPTIEMBRE 2015, 223-242

ISSN: 0004-0428, eISSN: 1988-8511, doi: 10.3989/aearte.2015.14 


\section{BIBLIOGRAFÍA}

Barlow-Meagher Co Building Construction (1945). Miscellaneous Stone Removed from the Blumenthal House for the Metropolitan Museum of Art New York. Nueva York.

Blanc, Monique (1999): Les frises oubliées de Vélez Blanco. Cat. Exp., París. Musée des Arts Décoratifs.

De Motos, Federico (1902): "El Castillo de Vélez Blanco", El Correo, Madrid, 16-VI, n. 4.

De Miñano, Sebastián (1826): Diccionario Geográfico-Estadístico de España y Portugal. Madrid, PierartPeralta, T. 9.

Díaz López, Julián Pablo / Lentisco Puche, José Domingo (2006): El señor en sus estados: diario de un viaje de D. Antonio Álvarez de Toledo, X marqués de los Vélez, a sus posesiones de los reinos de Granada y Murcia (octubre 1769 enero 1770). Vélez Rubio: Centro de Estudios Velezanos.

Espín Rael, Joaquín (1904a): "El alcázar de los Vélez: recuerdos". En: Boletín de la Sociedad Española de excursiones. Madrid, n. 137, Julio, pp. 134-135.

Espín Rael, Joaquín (1904b): “El alcázar de los Vélez: un monumento que nos quitan”. En: Boletín de la Sociedad Española de excursiones, n. 135, Madrid, pp. 101-103.

Lentisco Puche, José Domingo (coord.) (2007): El castillo de Vélez Blanco 1506-2006: Imagen y Memoria. Vélez Rubio: Centro de Estudios Velezanos, pp. 146-155.

Marañón, Gregorio (1962): Los tres Vélez. Madrid: Espasa-Calpe.

Motos Díaz, Ismael (2014): "La propuesta del Metropolitan Museum of Art de intercambio de elementos arquitectónicos del castillo de Vélez Blanco en 1963”. En: ph investigación [en línea], n. 2, junio, pp. 51-73 <http://www.iaph.es/phinvestigacion/index.php/ phinvestigacion/article/view/42>

Navarro, Antonio José / Castillo Fernández, Javier (2000): Viajes de un naturalista ilustrado por los reinos de Granada y Murcia. Murcia: Universidad de Murcia.

Nicolás Martínez, María del Mar (1995): "Fases de construcción de la Iglesia Parroquial de la Encarnación de Vélez Rubio. Aporte documental”. En: Martínez Padilla, Catalina (coord.): A la memoria de Agustín Díaz Toledo. Almería: Universidad de Almería, pp. 203-211.

Nicolás Martínez, María del Mar (2011): “Lujo, ostentación y poder. A propósito de la casa marquesal de los Vélez”. En: Camacho Martínez, Rosario, Asenjo Rubio, Eduardo y Calderón Roca, Belén (coord.): Creación artística y mecenazgo en el desarrollo cultural del Mediterráneo en la Edad Moderna, Málaga, Universidad de Málaga, pp. 65-91. En: <http://www.historiadelartemalaga.es/departamento/wp-content/>.

Raggio, Olga (1964): “The Velez Blanco Patio: An Italian Renaissance Monument from Spain”. En: The Metropolitan Museum of Art Bulletin, vol. XXIII, n. 4, Diciembre. Nueva York.

Roth, Dietmar (2007): "La visita de don Fernando Joaquín Fajardo, VI marqués de los Vélez, al castillo en 1657”. En: Lentisco Puche, José Domingo (coord.): El Castillo de Vélez Blanco: 1506-2006. Imagen y Memoria. Vélez Rubio: Centro de Estudios Velezanos, pp. 82-87.

Tapia Garrido, José Angel (1959): Vélez Blanco: la villa señorial de los Fajardo. Almería: Diputación Provincial de Almería.

Fecha de recepción: 05-II-2014

Fecha de aceptación: 16-VI-2014

Arch. esp. arte, LXXXVIII, 351, JULIO-SEPTIEMBRE 2015, 223-242

ISSN: 0004-0428, eISSN: 1988-8511, doi: 10.3989/aearte.2015.14 